\title{
The Cœlenterate Plankton of the Northumbrian Coast during the Year 1925.
}

\author{
By \\ Henry G. Watson, B.Sc.
}

With 1 Figure in the Text.

THIs is a report of the Cœlenterate plankton taken during the cruises of the Evadne in 1925, and investigated at the request of Professor A. D. Peacock. I am indebted to Miss Ann R. Sanderson, B.Sc., for considerable help in the identification of specimens.

The material was received from the Dove Marine Laboratory already separated from the whole catch of the plankton. In most cases only a fraction of the catch had been examined, but the numbers in the table express the total for the whole catch. Instead of hauls being taken at three depths as in previous years, hauls were taken at five depths, but the " mid-over" position was discontinued after April. All the hauls were made in daylight.

Reviewing the estimated numbers taken, it appears that on the whole the cœlenterates were not so abundant in 1925 as in previous years, Hybocodon prolifer L. Agassiz, and Aglantha rosea (Forbes) being the only species whose numbers compare at all favourably with those of former collections. Seventeen species were noted, seven occurring in middle and bottom waters only. No new species was found.

Cœlenterates were absent from several hauls taken in April, namely, off Beadnell (Sta. 1 surface, Sta. 2 surface) and off Coquet (Sta. 9 surface and mid-over).

For details regarding station, depth and numbers reference should ke made to Table $\mathbf{I}$ and Fig. 1 . The figures in Table 1 have been expressed proportionately in terms of the whole catch.

\section{ANTHOMEDUSE.}

Sarsia eximia Allman, and S. tubulosa (M. Sars).

In all only five specimens of these were found and each number in the table represents only one specimen. In the case of each $S$. eximia specimen, it was so badly mutilatcd as to be identifiable with difficulty. 


\section{Euphysa aurata (Forbes.)}

This was common in all localities in June and July, with a tendency to be found in the lower hauls. It was notably absent in September, a similar observation being made in the Reports of 1922 and 1923. A catch far greater than any other was taken off Newbiggin (Sta. 18 Bottom) on July 11th. Steenstrupia nutans (M. Sars), if present, was not identified.

\section{Hybocodon prolifer L. Agassiz.}

This was far more numerous at the two stations established on June 1st, one off Newbiggin, the other off Coquet, than at any other time and in each case in the middle hauls. It was rare in April and almost absent in the catches later in the year.

\section{Podocoryne areolata Alder.}

Only isolated specimens of this medusa occur.

Bougainvillia britannica Forbes.

This was found at all depths in June and July, but was entirely absent in April and September. The best catch was taken of Dunstanborough (Sta. 16), the middle haul being the largest. It may be noted that it was absent off Boulmer (Sta. 15) on the same day. The total of all specimens of medusæ from Station 15 is remarkably small.

\section{Lizzia blondina Forbes.}

The occurrence of this species was erratic, being found only at a few stations in small numbers at all depths. Its occurrence this year bears no resemblance to that of 1924 .

\section{Rathkea octopunctata (M. Sars).}

This uncommon species was a little more frequent in its appearance than in the previous year. The identification of each specimen was confirmed by the character of the oral tentacles.

\section{LEPTOMEDUS $\nexists$.}

\section{Mitrocoma fulva (Browne).}

This occurs in middle and bottom waters in April, June and July. A single specimen was found in the fraction from a surface haul taken off Alnmouth in September (Sta. 21). Its occurrence appears unusual. 


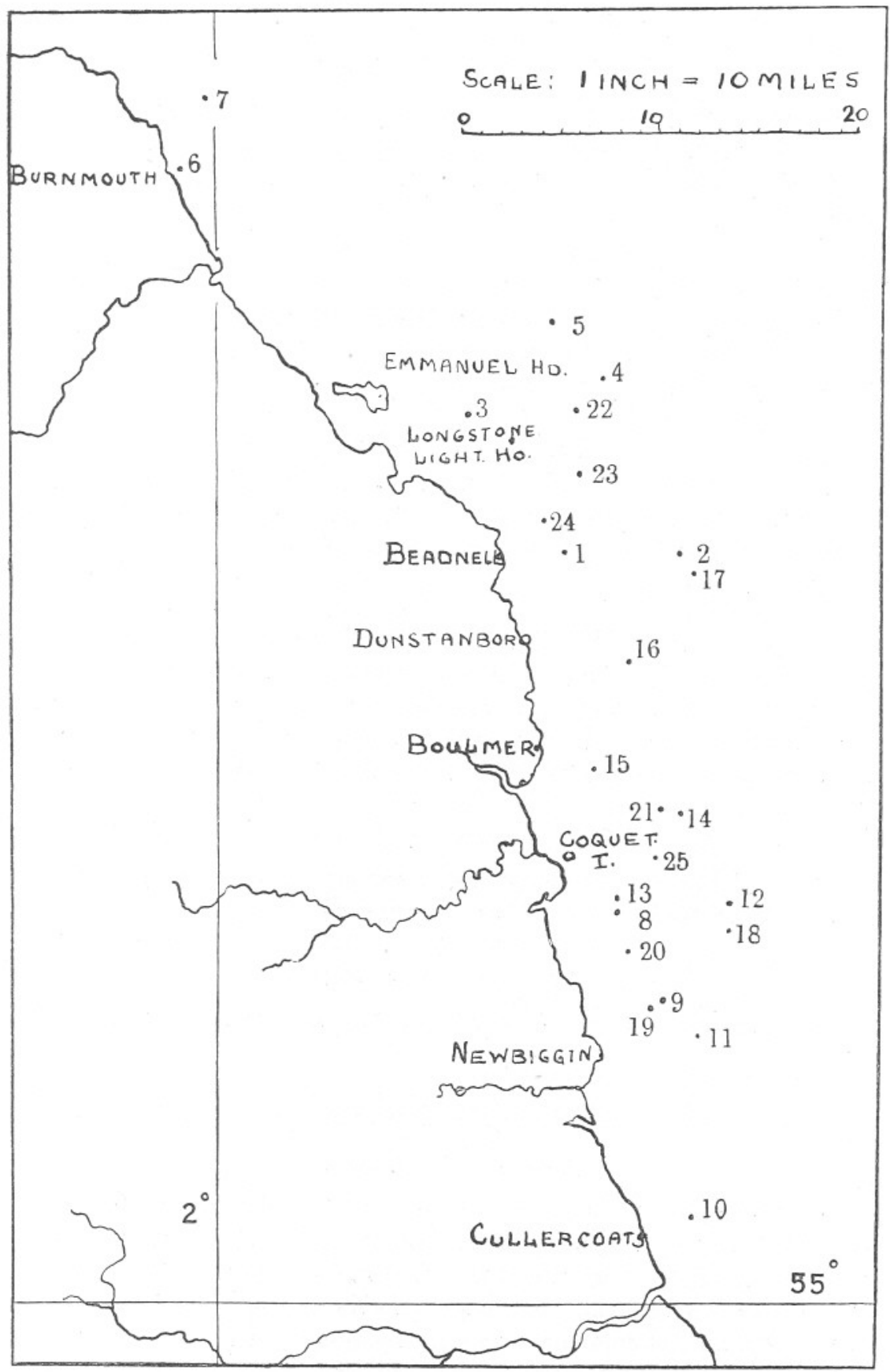

FIG. 1. 


\section{Cosmetira pilosella (Forbes).}

The single specimen obtained in April is doubtfully identified, being shrunken and much stained. The species occurred in small numbers in September in the lower waters only, the specimens being large if rot mature.

$$
\text { Tiaropsis multicirrata (M. Sars). }
$$

This species occurred again this year, but in small numbers. It appeared as last year, in April and not again until the latter part of July. The specimens obtained in April were small, about $1 \mathrm{~mm}$. across, while those in July were almost, if not, maiure.

\section{Obelia sp.}

The difficulty of distinguishing the medusæ of the various species has caused them to be numbered together. The numbers are a slight increase on those of the previous year, except in April, and they compare favourably with those of 1923 .

\section{Phialidium hemispharicum (Gronovius).}

The numbers of this medusa are less than in any of the two previous years. It was present at all depths with a tendency to be fourd in the lower hauls, a similar observation being made in previous years. Specimens of all sizes occurred throughout the whole collection.

\section{Eutonina indicans (Romanes).}

A total of 8 medium-sized specimens was obtained from three stations, namely, St. Abb's Head (Sta. 7), Newbiggin (Sta. 11) and Coquet (Sta. 14).

\section{Tima bairdii (Johnston).}

One specimen only was obtained, in the middle haul off Boulmer (Sta. 15).

\section{TRACHYMEDUS}

\section{Aglantha rosea (Forbes).}

This was by far the most abundant species. Though notably absent entirely from two stations (Burnmouth, Sta. 6, and Coquet, Sta. 12) it occurred in almost every one of the other hauls at all the other stations. It was equally common at all depths. The numbers seem to reach a peak at the beginning of September, though the largest catch by far was taken at the last station. The numbers compare favourably with those of other years. 
TABLE I.

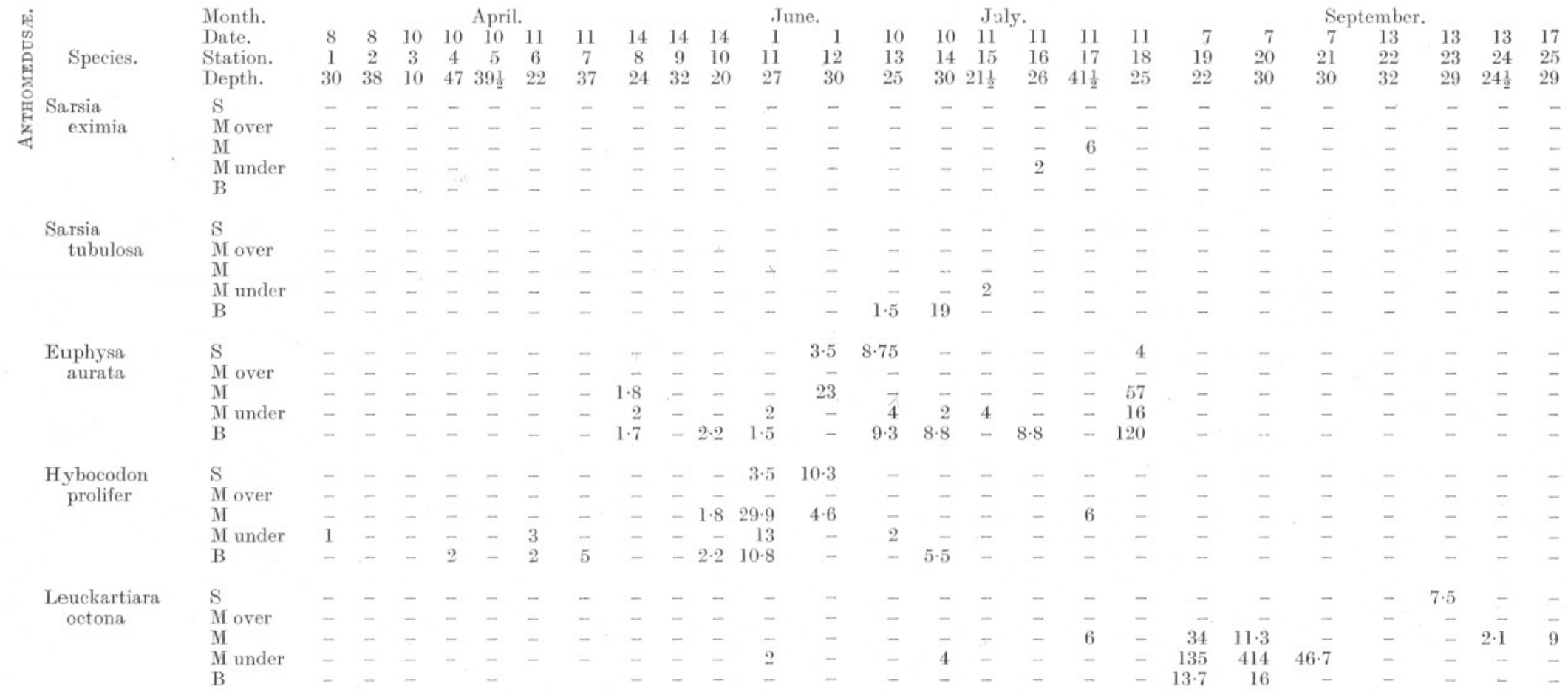


TABLE I-continued.

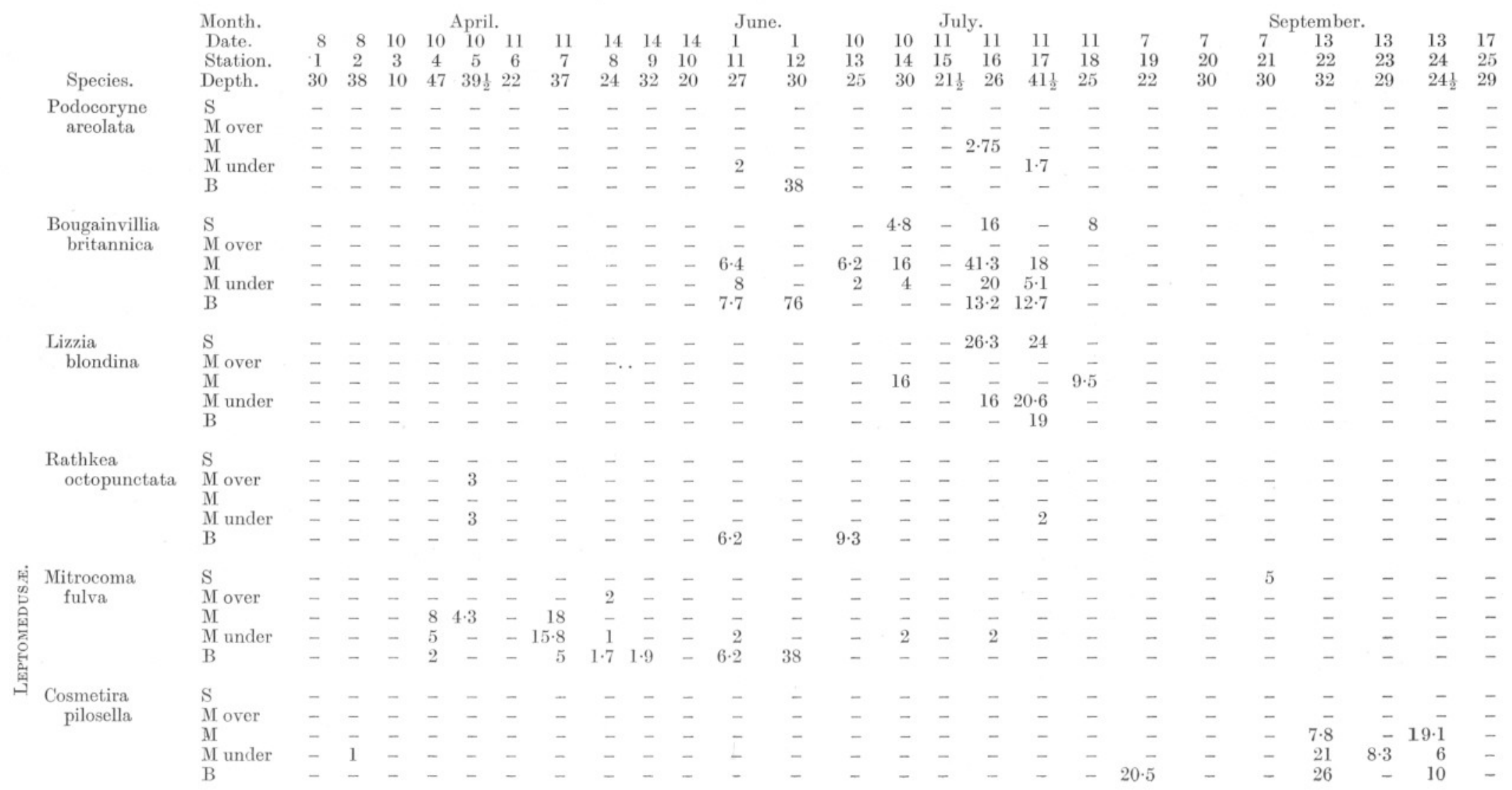




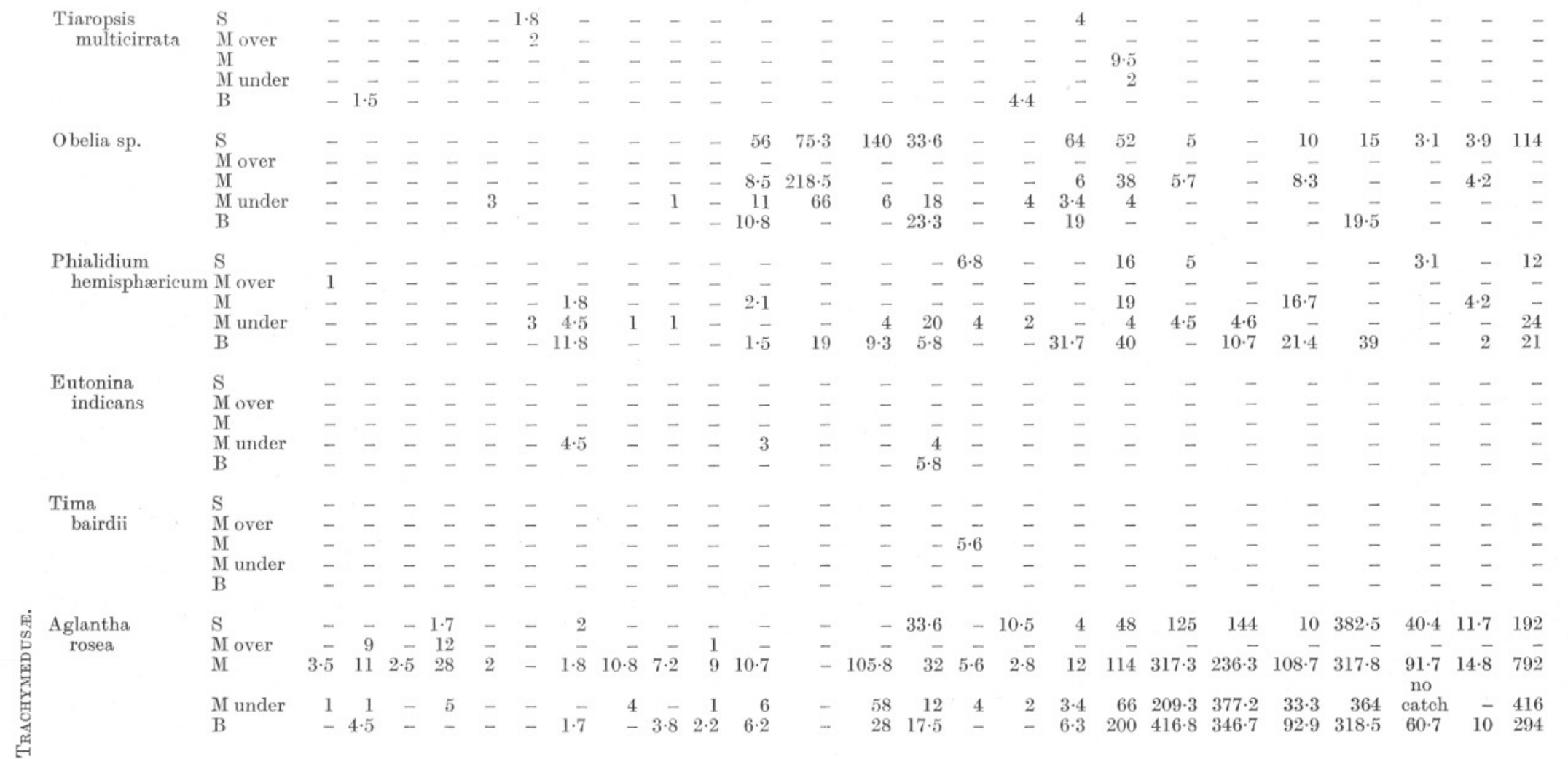


